\title{
A Novel Eddy Current Speed Sensor with Ferrite E-Core
}

\author{
Mehran Mirzaei ${ }^{1}$, Pavel Ripka ${ }^{1}$, and Vaclav Grim ${ }^{1}$ \\ ${ }^{1}$ Faculty of Electrical Engineering, Czech Technical University, Prague, 16627, Czech Republic
}

\begin{abstract}
This letter presents a novel speed sensor based on the motion induced eddy currents in conductive moving parts. The magnetic yoke is Ferrite core with E shape. The excitation coil is wound around the centre leg of the E-core and two antiserially connected pick up coils are located on the side legs. Solid iron and aluminum materials are considered for the moving part in the simulations and measurements. $2 \mathrm{D}$ and $3 \mathrm{D}$ finite element methods are used for the detailed analysis and the parametric calculations of the sensor. Excellent linearity is shown despite the sensor simple construction. The analysis and measurements are performed at different speeds and excitation frequencies to evaluate the sensor performance. The minimum achieved linearity error is $0.5 \%$.
\end{abstract}

Index Terms-Eddy currents, speed sensor, Ferrite E-core, iron, aluminum, finite element method, measurement.

\section{INTRODUCTION}

The speed measurement and assessment are vital in different applications with translational motion such as for railway (Fig. 1 a)) and rotating motion for control, maintenance and protection purposes [Addabbo 2019]. Various methods and technologies are currently used for the speed measurements such as optical sensors, capacitive sensors, magnetic reluctance and eddy current saliency based sensors. Some of these sensors are not resistant to the dust and dirt, the other are non-destructive [Li 2019, Manyala 2013].

Utilizing eddy current is a well known technique for different electromagnetic applications [Gonen 1965, Guilizzoni 2019, Tsukada 2019]. The eddy current speed sensor could be appropriate option for speed measurement as it is of non-contact nature with cost effective and simple configuration. Recent works in [Cardelli 2013, Itaya 2013, Sonoda 1985, Takehira 1988] concerning eddy current speed sensor were focused on the non-ferromagnetic moving conductive part, mainly aluminum, which is not commonly used material for moving objects in comparison with solid iron and steel. The speed measurement and performance analysis for ferromagnetic moving parts more complicated, because not only conductivity of the moving part, but also its magnetic permeability must be taken into the account.

The authors recently developed different types of eddy current speed sensor with iron and aluminum moving parts for rotating and translational motions [Mirzaei 2019a, Mirzaei 2019b, Mirzaei 2020a and Mirzaei 2020b]. These sensors were designed and analyzed both with the air core and magnetic yoke. The magnetic yoke was used to improve sensor sensitivity and for magnetic shielding purposes. The proposed eddy current sensor in this letter has new configuration with compact structure using Ferrite E-core, which gives considerably higher sensitivity. 2D time stepping finite element method (FEM) is used for fast parametric calculations of a new eddy current speed sensor. 3D FEM is also used for more precise verification and comparison to measurements at various speeds and frequencies.

\section{Eddy Current Speed Sensor Model}

Fig. $1 \mathrm{~b}$ ) shows 3D model of the proposed eddy current speed sensor for translational motion. The speed of the solid conductor moving part, $V$ is in the x-direction.

The model shows three rectangular coils, the middle one is the excitation coil and two side coils are antiserially connected pick up coils. The induced voltage in the antiserially connected pick up coils is zero at zero speed of the moving part because the left and right coils have the same mutual magnetic flux linkage with the excitation coil. For nonzero speed the symmetry is broken and the differential induced voltage is proportional to the speed value.

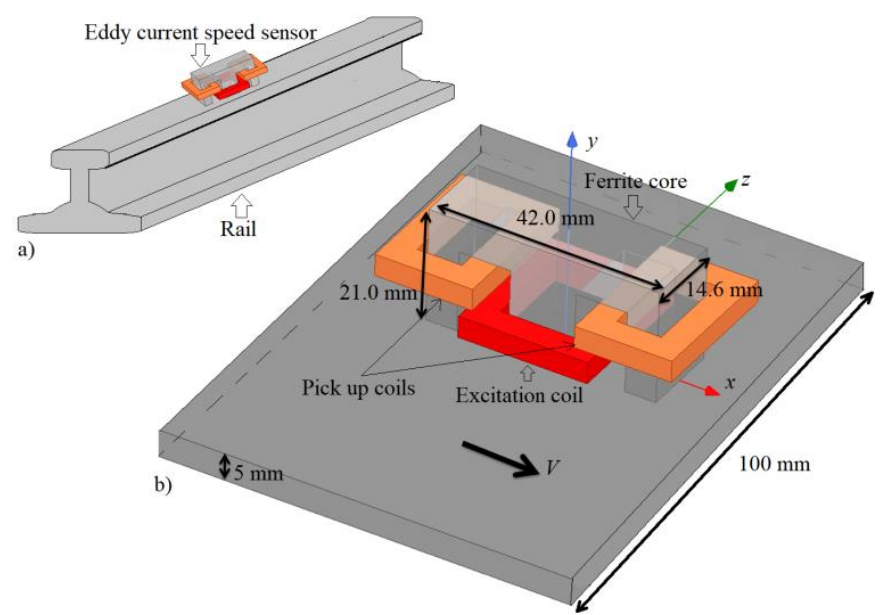

Fig. 1. a) Eddy current speed sensor with linear translational motion for railway application b) detailed model

Equation (1) presents induced eddy current, $J_{\mathrm{e}}$ in the conductive 
moving part with smooth (non-salient) surface in the translational motion direction [Hammond 1971, Binns 1992]. First term and second term in the right side of eq. (1) are transformer component caused by the time variation of the source field and the motional component, respectively [Hammond 1971]. The reaction fields of the motional component of the induced eddy current, $J_{\mathrm{e}}$ cause unequal and asymmetric magnetic flux distribution in the left and right legs of the E-core and in the corresponding pick up coils.

$$
J_{e}=-\sigma \cdot \frac{\partial A}{\partial t}+\sigma \cdot V \times \nabla \times A, \quad B=\nabla \times A
$$

(1)

where, $\sigma, A$ and $B$ are electrical conductivity of moving conductive part, magnetic vector potential and magnetic flux density.

\section{Parametric Analysis of Eddy Current Speed Sensor}

The distribution of induced eddy current in the conductive moving part has 3D configuration [Bolton 1969], which requires 3D modeling for the analysis of eddy current speed sensor. However, 2D time stepping FEM taking into the account moving the moving part speed is used for the parametric calculations of the eddy current sensor performance despite its less accuracy in comparison with time stepping 3D FEM. 2D FEM is faster, which makes it more suitable for parametric analysis. The maximum linear speed is considered 14.1 $\mathrm{m} / \mathrm{s}$ in this paper. Fig. 2 shows the magnetic flux distribution at 14.1 $\mathrm{m} / \mathrm{s}$ using 2D time stepping FEM [Ansys/Maxwell 2019], which shows asymmetric magnetic flux distribution due to the moving part speed. Asymmetric magnetic flux in the Ferrite core causes different flux linkage and induced voltage in the pickup coils. The third dimension effects are neglected in 2D FEM analysis.

Fig. 3 presents variations of differential induced voltage of the pick up coils versus relative permeability, $\mu_{\mathrm{r}}$ and electrical conductivity, $\sigma$ for iron moving part and nonmagnetic moving part (for example, aluminum or copper). The induced voltage in the iron moving part increases with decreasing relative permeability and increasing conductivity at $120 \mathrm{~Hz}$ and $800 \mathrm{~Hz}$. The induced voltage at $800 \mathrm{~Hz}$ is less sensitive to the materials properties of the iron moving part (variations less than 15\%) in comparison with induced voltage at 120 $\mathrm{Hz}$ (variation less than 25\%). The ranges of variations for relative permeability and electrical conductivity are considered between 75 to 125 and $4 \mathrm{MS} / \mathrm{m}$ to $6 \mathrm{MS} / \mathrm{m}$, which are quite common values for different construction irons and steels [Mirzaei 2020c]. The induced voltage variations versus conductivity for nonmagnetic moving part show different tendency at $120 \mathrm{~Hz}$ and $800 \mathrm{~Hz}$. The variation of induced voltage is more sensitive to the conductivity at $800 \mathrm{~Hz}$ rather than $120 \mathrm{~Hz}$. The induced voltage increases with increasing frequency until $800 \mathrm{~Hz}$ for the iron moving part with relative permeability 100 and conductivity 6.0 MS/m (Fig. 4). However the induced voltage has maximum value at about $200 \mathrm{~Hz}$ and it decreases for the aluminum moving part with conductivity $33.5 \mathrm{MS} / \mathrm{m}$. The flux linkages decrease versus frequency for both iron and aluminum moving parts, which shows that difference of magnetic flux densities at left and right sides of excitation coil, has highest sensitivity at low frequencies or DC. It is contrary to the variation of induced voltage versus frequency, which in the ideal case is linear due to the induction law.

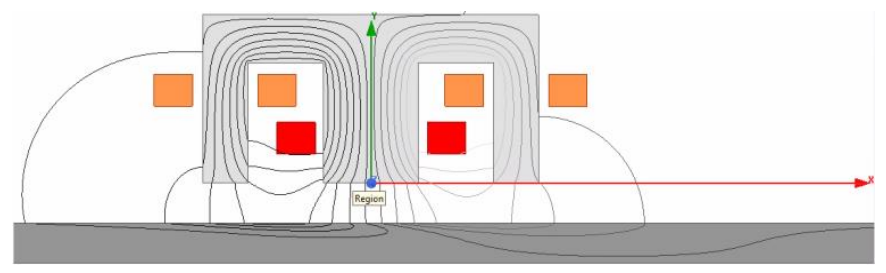

Fig. 2. Magnetic flux distribution at $120 \mathrm{~Hz}$ and $14.1 \mathrm{~m} / \mathrm{s}$ for moving iron part using 2D FEM
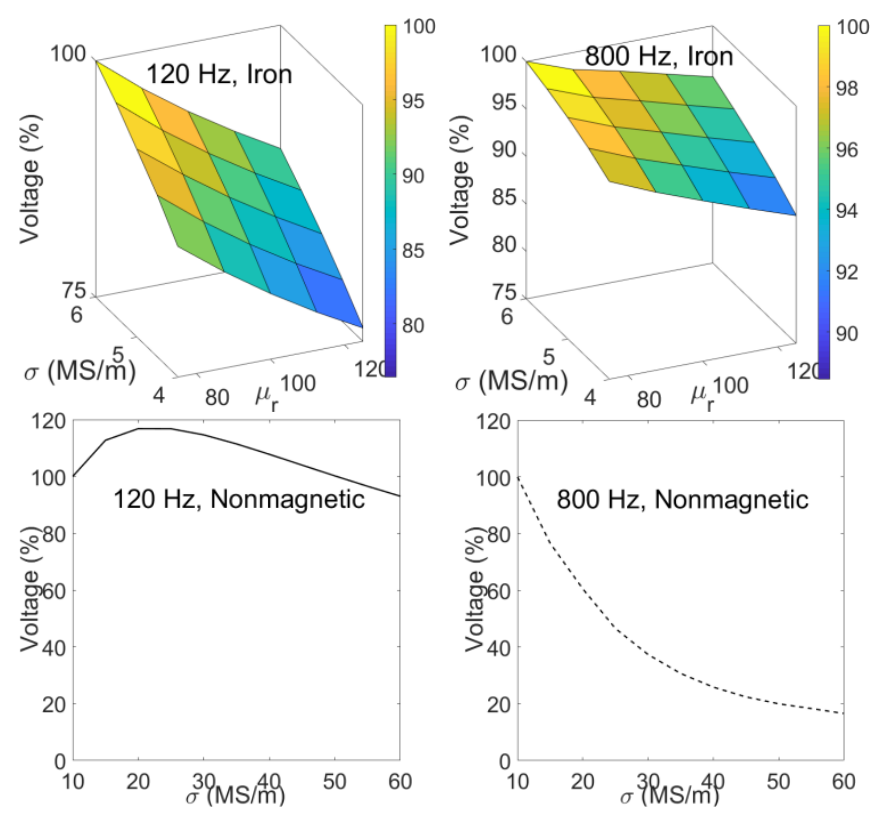

Fig. 3. Relative variation of the induced voltage versus moving part material properties at $14.1 \mathrm{~m} / \mathrm{s}$ for ferromagnetic iron and nonmagnetic moving parts
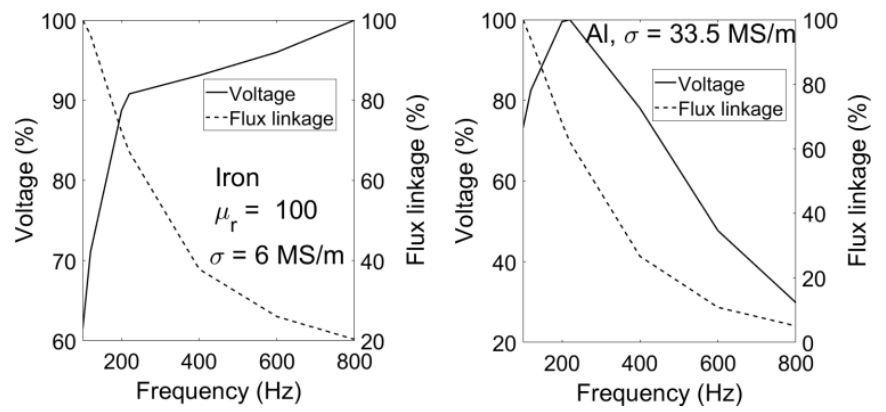

Fig. 4. Relative variation of the induced voltage versus frequency at $14.1 \mathrm{~m} / \mathrm{s}$

\section{Experimental Results}

Eddy current sensor structure and measurement elements are shown in Fig. 5. Rotating iron and aluminum disks are used to model moving part in the experimental set up. It is expedient to utilize disk or cylinder to model linear motion [Iwamoto 1973, Coho 1975]. A signal generator with internal resistance, $R_{\text {in }}=50 \Omega$ is used as a source for the excitation coil. Induced voltages are measured using a SR 860 lock-in amplifier at different frequencies and moving part speeds. The real and imaginary components of the induced voltage are measured relative to the excitation coil current as reference signal.

The number of turns per coil is 1000 . Resistance and inductance of the excitation coil mounted on the Ferrite core without conductive 
moving part nearby are measured $R_{\mathrm{c}}=166 \Omega$ and $L_{\mathrm{c}}=89.25 \mathrm{mH}$, respectively. The excitation coil inductance variation versus frequency with magnetic and mechanical gap of $5 \mathrm{~mm}$ between the ferrite core and moving part is shown in Fig. 6. The inductance is decreasing with frequency due to the reaction fields of the induced eddy current. The measured excitation current, $I_{\mathrm{rms}}$ decreases with frequency, $f$ as the source voltage, $U_{\mathrm{s}}$ is constant: $I_{r m s}=U_{s} /$ $\sqrt{\left(R_{\text {in }}+R_{c}\right)^{2}+\left(2 \pi f L_{c}\right)^{2}}$.

The measured induced voltages of the antiserially connected pick up coils are shown in Figs. 7 and 8 at different frequencies between $14.1 \mathrm{~m} / \mathrm{s}$ and $+14.1 \mathrm{~m} / \mathrm{s}$ for the moving part. The sensitivity and linearity of the real and imaginary induced voltage of eddy current speed sensor show different tendency for iron and aluminum moving parts, which shows significant effects of the moving part materials. All results for the real and imaginary components of the induced voltage show roughly ideal linear curve versus speed between $-5 \mathrm{~m} / \mathrm{s}$ and $+5 \mathrm{~m} / \mathrm{s}$ for iron and aluminum moving parts. The real component $(\mathrm{Re})$ of the induced voltage for the iron moving part has the finest linearity at higher frequencies for the whole speed range, $\pm 14.1 \mathrm{~m} / \mathrm{s}$. The imaginary component (Im) of induced voltage curve is less linear. The sensitivity of the eddy current speed sensor increases versus speed for the iron moving part with same excitation coil current. The sensitivity is higher for aluminum moving part at low frequencies and it is higher for iron moving part at higher frequencies. The absolute component of induced voltage, $U_{a}$ is calculated with imaginary value, $U_{i}$ and real value, $U_{r}: U_{a}=\sqrt{U_{r}^{2}+U_{i}^{2}}$. Table 1 presents sensitivity coefficient, $C$ for the iron moving part using Fig. 7.

Table 1. Sensitivity coefficients at $400 \mathrm{~Hz}$ and $800 \mathrm{~Hz}, U=C \cdot V$

\begin{tabular}{lcc}
\hline \hline Case for iron moving part & $400 \mathrm{~Hz}$ & $800 \mathrm{~Hz}$ \\
\hline Real & $4.45 \mathrm{mV} / \mathrm{m} / \mathrm{s}$ & $3.41 \mathrm{mV} / \mathrm{m} / \mathrm{s}$ \\
Imaginary & $2.50 \mathrm{mV} / \mathrm{m} / \mathrm{s}$ & $1.65 \mathrm{mV} / \mathrm{m} / \mathrm{s}$ \\
Absolute & $5.10 \mathrm{mV} / \mathrm{m} / \mathrm{s}$ & $3.79 \mathrm{mV} / \mathrm{m} / \mathrm{s}$ \\
\hline \hline
\end{tabular}
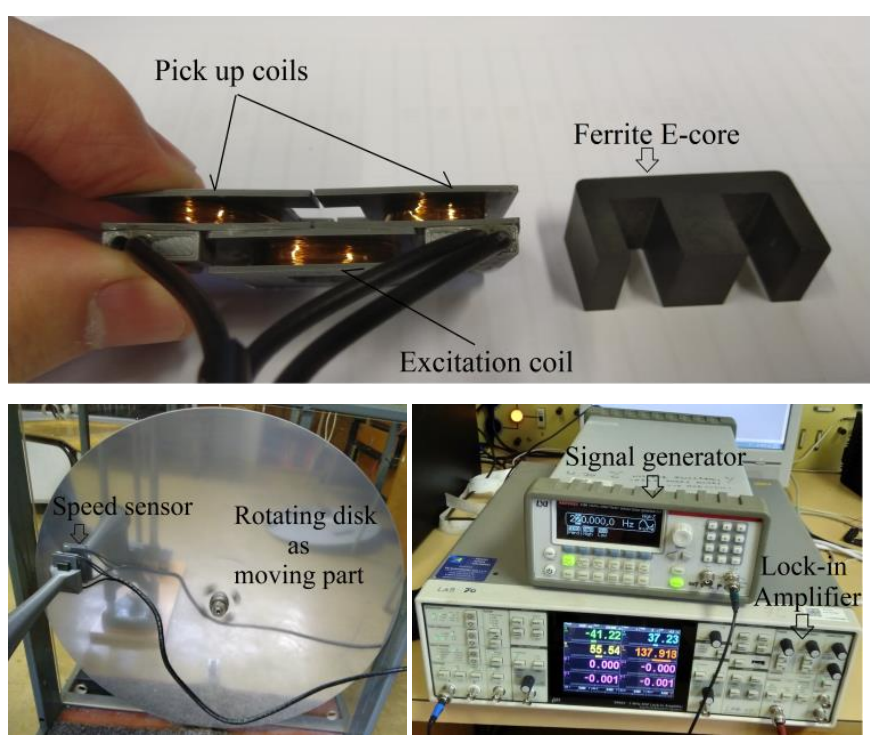

Fig. 5. Experimental set up - Speed sensor with Ferrite E-core and coils, rotating disk to model linear speed and instruments used to deliver excitation current and process the induces voltage
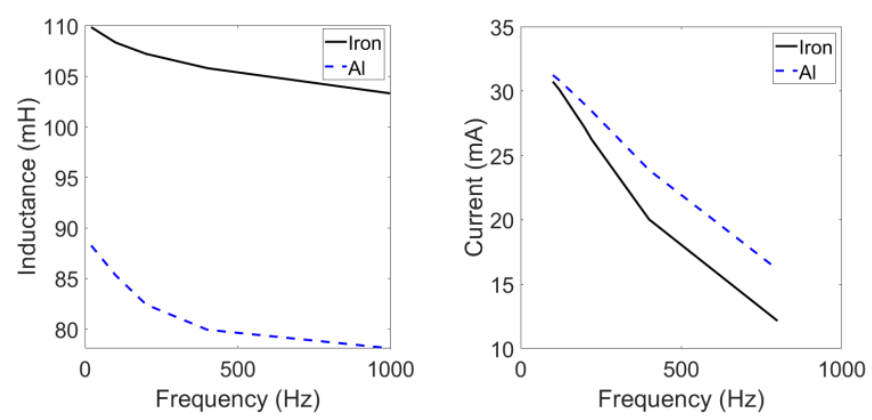

Fig. 6. Excitation coil inductance and excitation coil current (rms) versus frequency at constant input source voltage $7.07 \mathrm{~V}$ (rms)
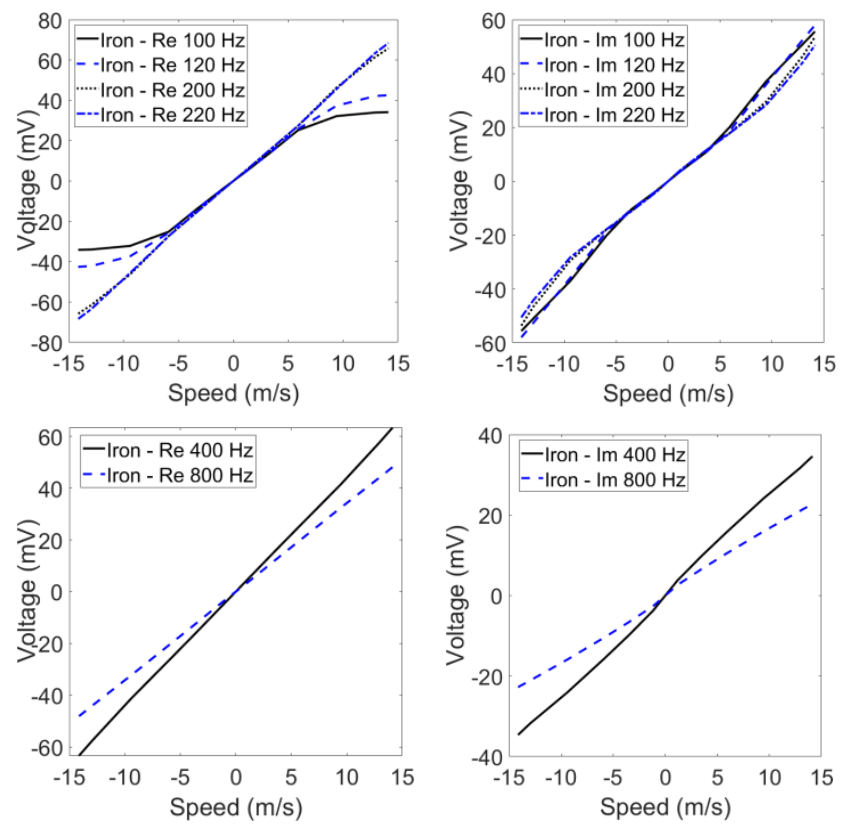

Fig. 7. Real and imaginagry components of induced voltages (rms) versus speed at different frequencies - Iron moving part
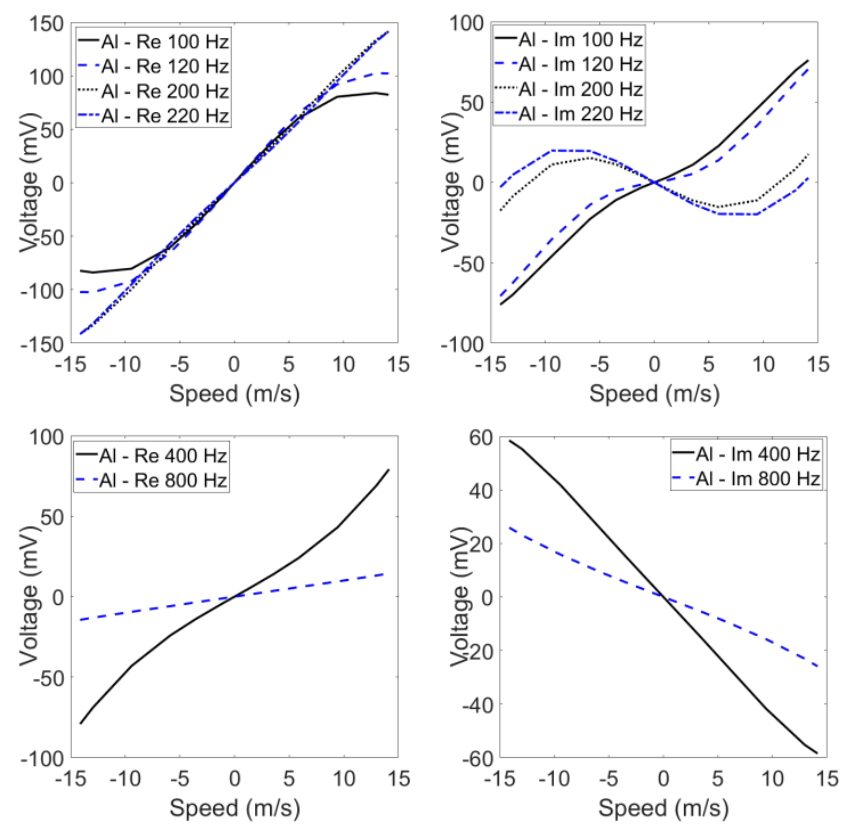

Fig. 8. Real and imaginagry components of induced voltages (rms) versus speed at different frequencies - Aluminum moving part 


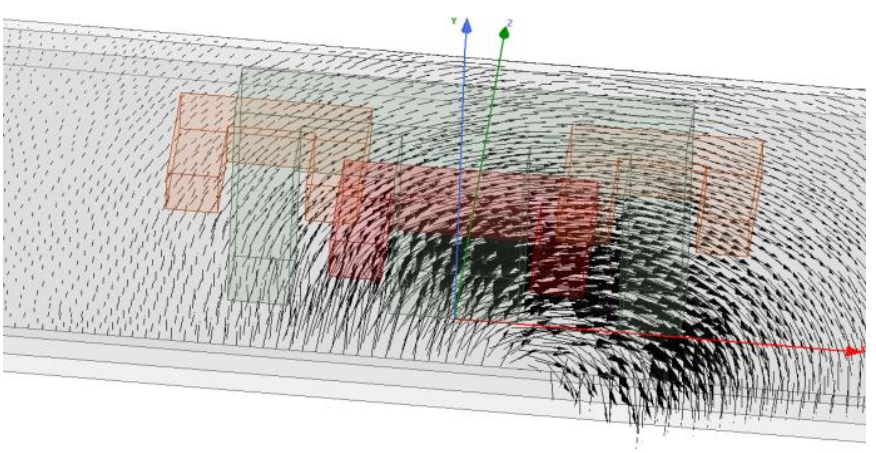

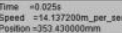

Fig. 9. Eddy current distribution in the moving part of half model at 120 $\mathrm{Hz}$ and $14.1 \mathrm{~m} / \mathrm{s}$

Table 2. Comparison between experimental results and 2D and 3D FEM for iron $\left(\mu_{\mathrm{r}}=100, \sigma=6 \mathrm{MS} / \mathrm{m}\right)$ and aluminum $(\sigma=33.5 \mathrm{MS} / \mathrm{m})$ moving parts

\begin{tabular}{lcc}
\hline \hline \multirow{2}{*}{ Case } & Iron (Ir) & Aluminum (Al) \\
& Exp. & Exp. \\
& 2D FEM/3D FEM & 2D FEM/3D FEM \\
\hline $120 \mathrm{~Hz}, 14.1 \mathrm{~m} / \mathrm{s}$ & 71.9 & 124.2 \\
& $84.9 / 76.2$ & $77.4 / 122.5$ \\
$120 \mathrm{~Hz}, 5.9 \mathrm{~m} / \mathrm{s}$ & 31.7 & 66.8 \\
& $37.6 / 35.0$ & $43.6 / 67.3$ \\
$220 \mathrm{~Hz}, 14.1 \mathrm{~m} / \mathrm{s}$ & 85.1 & 141.5 \\
& $94.7 / 92.0$ & $86.6 / 143.9$ \\
$220 \mathrm{~Hz}, 5.9 \mathrm{~m} / \mathrm{s}$ & 32.5 & 60.1 \\
& $34.5 / 33.4$ & $35.9 / 61.6$ \\
\hline \hline
\end{tabular}

Fig. 9 shows induced eddy current distributions, which depicts asymmetric shape because of the moving part speed effects. The calculated results using 2D and 3D time stepping FEM in comparison with measurements are presented in Table 2. The measured conductivities of material of iron moving part and aluminum moving part are $6.0 \mathrm{MS} / \mathrm{m}$ and $33.5 \mathrm{MS} / \mathrm{m}$, respectively. 3D FEM results are more close to the experimental results especially for the aluminum moving part, which third dimensions effects is considered in 3D FEM. The discrepancies between 3D FEM and measurements for iron moving part could be because of relative magnetic permeability, which maybe different than $\mu_{\mathrm{r}}=100$.

\section{LINEARITY ANALYSIS}

Fig. 10 presents the error analysis in percent of full range of real, imaginary and absolute (Abs) components of induced voltage for the iron moving part at $400 \mathrm{~Hz}$ and $800 \mathrm{~Hz}$. The minimum linearity error is obtained less than $0.5 \%$ for real component of induced voltage at $800 \mathrm{~Hz}$. The linearity error of absolute component is lower than imaginary component and it is higher than real component. The linearity error is higher in the imaginary component of induced voltage as the imaginary component is more sensitive to the magnetic variation between magnetic core and moving part, which is probably caused by moving disk vibration [Mirzaei 2020a]. The magnetic gap variation is common problem in practical applications, for example, speed measurements in the railway transportation. It could be suggested that real component of induced voltage to be utilized for speed measurement and imaginary component for the compensation of the gap variation.
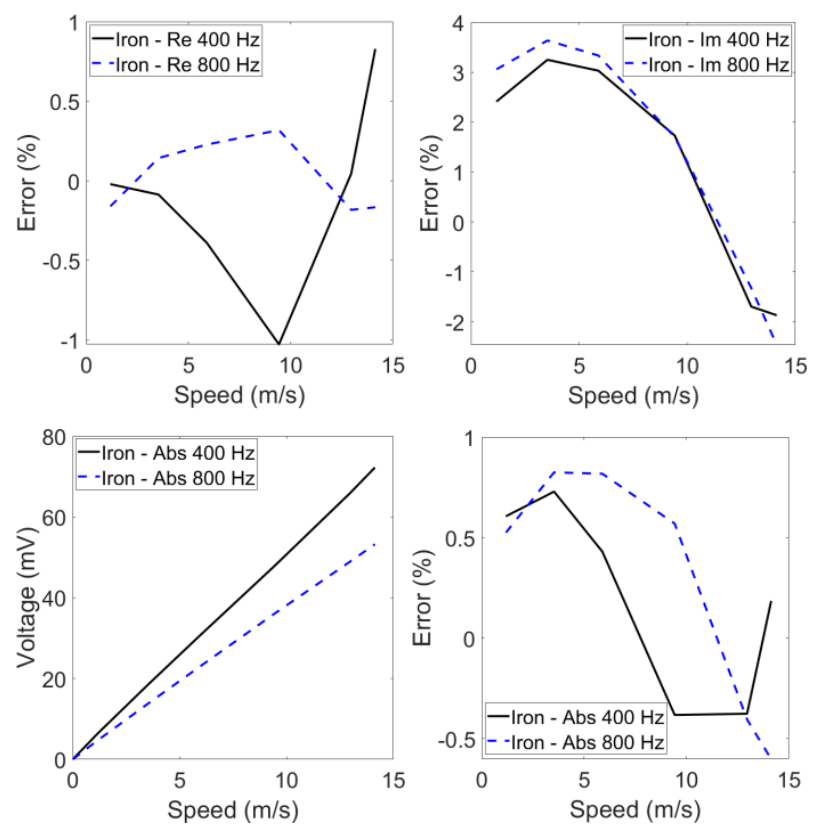

Fig. 10. Linearity error versus speed at different frequencies - Iron moving part

The methodologies of multi frequency and phase signature for compensations of the gap variation and effects of temperature and materials of moving part were investigated in [ $\mathrm{Lu} \mathrm{2018,} \mathrm{Lu} \mathrm{2019].} \mathrm{It}$ could be suggested that using simultaneously double frequencies excitation $400 \mathrm{~Hz}$ and $800 \mathrm{~Hz}$ can be proposed as one frequency is utilized for the speed meter and another frequency for compensation.

\section{CONCLUSION}

The presented linear eddy current speed sensor shows promising performance in terms of sensitivity and linearity. FEM simulations have been presented for performance analysis of the eddy current speed sensor. The differential voltage between two pick up coils is used as speed meter in the proposed speed sensor. Detailed linearity analysis was only presented for iron moving part as iron is the most common used material for industrial applications especially for high speeds. The merits of proposed sensor and motivations of the authors are cost effective, compact and simple structure and signal processing unit. The main limitation of the proposed speed sensor could be temperature compensating for harsh and hot environments. High linearity is preferred in full speed range for the sensor performance to avoid additional linearity improvement using, for example, software and simplify signal processing of sensor. It is observed that higher frequency is more suitable for higher speed range because of higher linearity in the full speed range.

The measurements and simulations of the eddy current speed sensor were performed for speed range $\pm 14.1 \mathrm{~m} / \mathrm{s}$ at different frequencies from $100 \mathrm{~Hz}$ to $800 \mathrm{~Hz}$. The material of moving part has essential effects for the performance of eddy current speed sensor.

The power consumption of the eddy current speed sensor at $30 \mathrm{~mA}$ excitation current is only $0.15 \mathrm{~W}$. The current of the excitation coil decreases with frequency under constant voltage source due to the reactance voltage of the coil, which is dependent on the frequency. The compensation of materials effects, lift off and moving part temperature must be considered for industrial applications, but these studies are beyond the scope of this letter. 


\section{ACKNOWLEDGMENT}

The authors thank Mr. A. Chirtsov and Dr. J. Vyhnanek from the Department of Measurement, Faculty of Electrical Engineering of the Czech Technical University for their support in building the eddy current speed sensor components and in preparing the measurement elements. This work was supported in part by Czech Technical University under Grant SGS18/187/OHK3/3T/1.

\section{REFERENCES}

Addabbo T, Di Marco M, Fort A, Landi E, Mugnaini M, Vignoli V, and Ferretti G (2019), "Instantaneous rotation speed measurement system based on variable reluctance sensors for torsional vibration monitoring," IEEE Trans. Instrum. Meas., vol. 68, pp. 2363-2373, doi: 10.1109/TIM.2018.2877808

Ansys/Maxwell software (2019), accessed on 27.04.2020: https://www.ansys.com/products/electronics/ansys-maxwell

Binns K J, Lawrenson P J, and Trowbridge C W (1992), The Analytical and Numerical Solution of Electric and Magnetic Fields. Wiley-Blackwell

Bolton H (1969), "Transverse edge effect in sheet-rotor induction motors," Proc. of the Inst. of Elect. Eng., vol. 116, pp. 725 - 731, doi: 10.1049/piee.1969.0144

Cardelli E, Faba A, and Tissi F (2013), "Contact-less speed probe based on eddy currents," IEEE Trans. Magn., vol. 49, pp. 3897-3900, doi: 10.1109/TMAG.2013.2248701

Coho O C, Kliman G B, and Robinson J I (1975), "Experimental evaluation of a high speed double sided linear induction motor," IEEE Trans. on Power App.\& Syst., vol. 94, pp. 10-18, doi: 10.1109/T-PAS.1975.31818

Gonen D, Stricker S (1965), "Analysis of an eddy-current brake," IEEE Trans. on Power App.\& Syst., vol. 84, pp. 357-361, doi: 10.1109/TPAS.1965.4766206

Gong C, Tuysuz A, Flankl M, Stolz T, Kolar J, Habetler T (2019), "Experimental analysis and optimization of a contactless eddy-current-based speed sensor for smooth conductive surfaces," IEEE Trans. on Indus. Electron., doi: 10.1109/TIE.2019.2946547

Guilizzoni R, Finch G, and Harmon S (2019), "Subsurface corrosion detection in industrial steel structures," IEEE MAG. Letters, vol. 10, 2108005, doi: 10.1109/LMAG.2019.2948808

Hammond P (1971), Applied Electromagnetism. Pergamon Press Ltd., Headington Hill Hall, Oxford

Li L, Hu H, QinY, and TangK (2019), "Digital approach to rotational speed measurement using an electrostatic sensor," Sensors (Basel), vol. 19, 2540, doi: $10.3390 / \mathrm{s} 19112540$

Itaya T, Ishida K, Tanaka A, and Takehira N (2013), “Analysis of an eddy current speed meter by rectangular coil system," IEEJ Trans. on Fund. and Mat., pp. 416-423, doi: 10.1541/ieejfms. 133.416

Iwamoto M, Ohno E, Itoh T, Shinryo Y (1973), “End-Effect of High-Speed Linear Induction Motor," IEEE Trans. on Ind. App., vol. 9, pp. 632-639, doi: 10.1109/TIA.1973.349986

Lu M, Zhu W, Yin L, Peyton A J, Yin W, and Qu Z (2018), "Reducing the lift-off effect on permeability measurement for magnetic plates from multi frequency induction data," IEEE Trans. on Inst. and Meas., vol. 67, pp. 167-174, doi: 10.1109/TIM.2017.2728338

Lu M, Huang R, Yin W, Zhao Q, Peyton A (2019), “Measurement of permeability for ferrous metallic plates using a novel lift-off compensation technique on phase signature,” IEEE Sens. J., vol. 19, pp. 7440-7446, doi: 10.1109/JSEN.2019.2916431

Manyala J O, Fritz T, and Atashbar M Z (2013), "Gearbox speed sensor design and performance optimization," IEEE Sensors J., vol. 13, pp. 629-636, doi: 10.1109/JSEN.2012.2224862

Mirzaei M, Ripka P, Chirtsov A, and Vyhnanek J (2019a), "Eddy current linear speed sensor," IEEE Trans. Mag., vol. 55 , 4000304, doi: 10.1109/TMAG.2018.2872123

Mirzaei M, Ripka P, Vyhnanek J, Chirtsov A and Grim V (2019b), "Rotational eddy current speed sensor," IEEE Trans. Mag., vol. 55, 4003710, doi: 10.1109/TMAG.2019.2918163

Mirzaei M, Ripka P, Chirtsov A, Vyhnanek J, and Grim V (2020a), "Design and modeling of a linear speed sensor with a flat type structure and air coils," J. of Magnetism and Magnetic Materials, vol. 495, 165834, doi: 10.1016/j.jmmm.2019.165834

Mirzaei M, Ripka P, Chirtsov A, and Grim V (2020b), "Eddy current speed sensor with magnetic shielding," J. of Magnetism and Magnetic Materials, vol. 502, 166568, doi: 10.1016/j.jmmm.2020.166568

Mirzaei M, Ripka P, Chirtsov A, and Grim V (2020c), "Temperature stability of the transformer position transducer for pneumatic cylinder," J. of Magnetism and Magnetic Materials, vol. 503, 166636, doi: 10.1016/j.jmmm.2020.166636

Sonoda T, Ueda R, Fujitani K, Irisa T, and Tatata S (1985), "DC magnetic field type eddy current speed sensor detecting cross magnetization field with amorphous core," IEEE Trans. Magn., vol. 21, pp. 1732-1734, doi: 10.1109/TMAG.1985.1064042
Takehira N, and Tanaka A (1988), "Analysis of a perpendicular-type eddy-current speed meter," IEE Proc. A - Phys. Science, Meas. and Instr., Manag. and Educ.- Rev., vol. 135 , pp. 89 - 94, doi: 10.1049/ip-a-1.1988.0014

Tsukada K, Shobu H, Goda Y, Kobara T, Sakai K, Kiwa T, and Saari M M (2019), "Integrated magnetic sensor probe and excitation wire for nondestructive detection of submillimeter defects," IEEE MAG. Letters, vol. 10, 8105105, doi: 10.1109/LMAG.2019.2936392 